\title{
Idiopathic Postpartum Intussusception: A Rare Cause of Acute Abdominal Pain
}

\author{
Ercan Kocakoc Zulkif Bozgeyik Mustafa Koc Mehtap Balaban \\ Department of Radiology, Faculty of Medicine, Firat University, Elazig, Turkey
}

\section{Key Words}

Idiopathic intussusception • Pregnancy • Ultrasound • Computed tomography

\begin{abstract}
Objectives: To present a case with acute abdominal pain due to idiopathic intestinal intussusception diagnosed by ultrasound and computed tomography (CT) during the early postpartum period. Clinical Presentation and Intervention: A 21-year-old female patient was admitted to our hospital with abdominal pain, nausea and emesis after a normal vaginal delivery. Laboratory tests done at admission were within normal limits except for leukocytosis. Physical examination revealed abdominal distention, guarding and rebound tenderness. Abdominal ultrasound and oral contrastenhanced CT showed a complex mass in the hypogastrium, with a typical configuration of intussusception. Emergent laparotomy revealed ileoileal invagination approximately $70 \mathrm{~cm}$ to the ileocecal valve but no lead point. A partial ileal resection was performed. Conclusion: This case shows that when intussusception is suspected, an abdominal ultrasound should be performed even in patients with atypical symptoms. CT may be used to confirm the diagnosis.
\end{abstract}

Copyright $\odot 2010$ S. Karger AG, Basel
(C) 2010 S. Karger AG, Basel

$1011-7571 / 10 / 0192-0163 \$ 26.00 / 0$

Fax +4161306 1234

E-Mail karger@karger.ch

www.karger.com
Accessible online at:

www.karger.com/mpp

\section{Introduction}

In adults, intussusception is a rare, but potentially serious, condition that usually presents with mechanical obstruction and requires surgical management $[1,2]$. Intussusception typically occurs in patients who have benign or malignant conditions affecting the distal small intestine or colon; $70-90 \%$ of patients have a lead point. Because presenting symptoms are often nonspecific, only approximately $50 \%$ of patients can be diagnosed based on clinical features alone $[1,2]$. Hence, imaging should be considered when intussusception is suspected.

While computed tomography (CT) is the imaging modality most frequently used to identify intussusception, this case report shows that ultrasound can also make the diagnosis in a case of idiopathic intestinal intussusception during the early postpartum period.

\section{Case Report}

A 21-year-old female patient was admitted to our hospital with abdominal pain, nausea and emesis after normal vaginal delivery. Her vital signs were normal (blood pressure: 120/70 mm Hg; heart rate: $72 / \mathrm{min}$; body temperature: $36.5^{\circ} \mathrm{C}$ ). Laboratory data on admission were within normal limits except for leukocytosis. Physical examination revealed abdominal distention, guarding and rebound tenderness. Plain film showed air-fluid levels consistent 

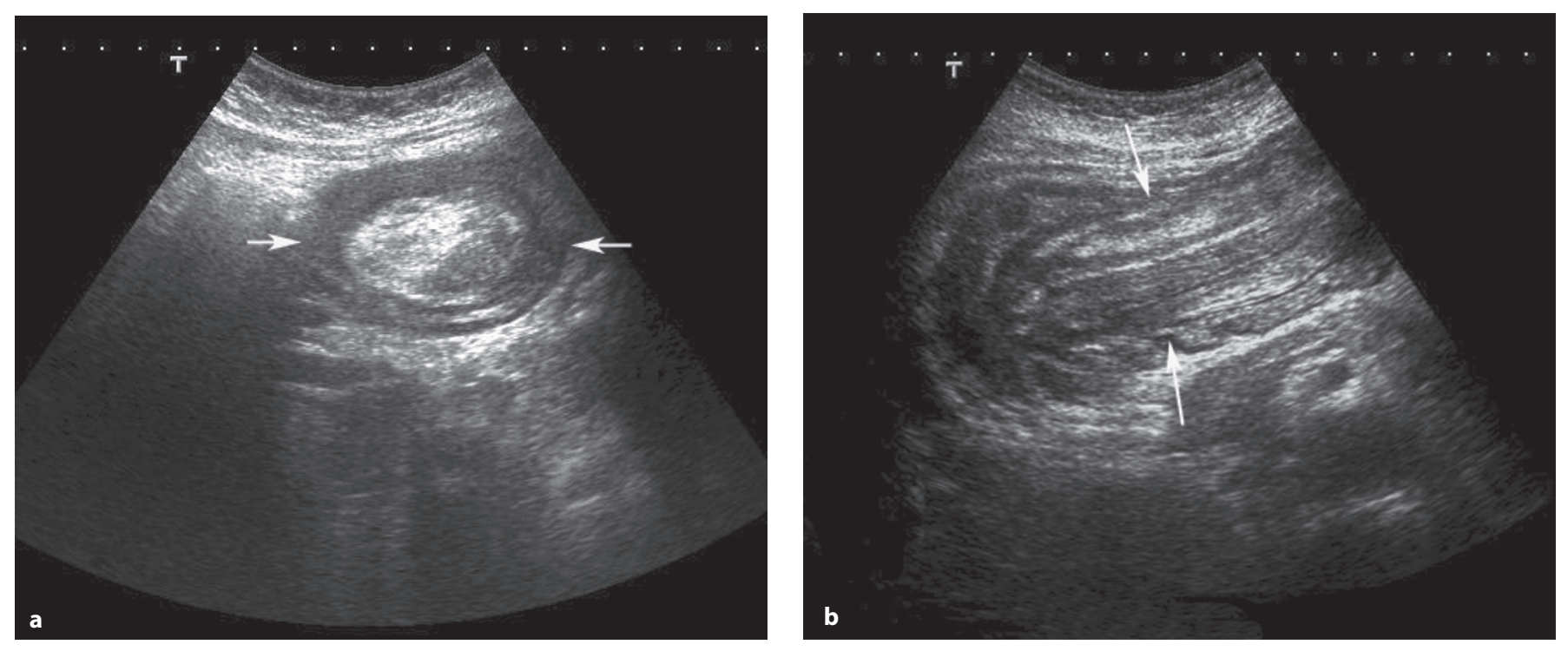

Fig. 1. a Transverse abdominal sonography: in the left lower quadrant, a 'bull's eye or doughnut' image with an echogenic center and a translucent rim (arrows) is visible. b Longitudinal ultrasound scan showing the 'pseudokidney' sign, representing the appearance of the intussusceptum and intussuscipiens (arrows).

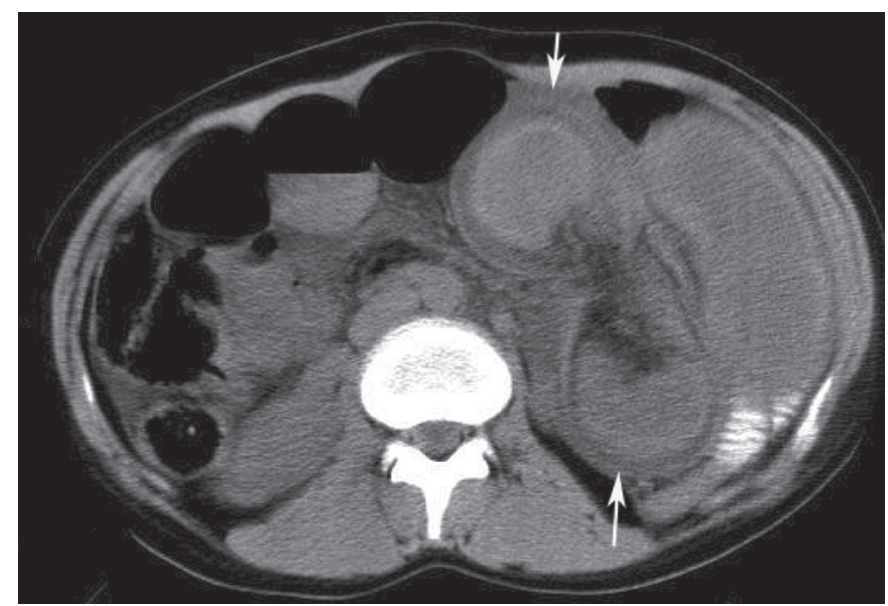

Fig. 2. Oral contrast-enhanced CT showing a round target-shaped mass in the left mid-abdomen consisting of different densities with distended fluid-filled small-bowel loops (arrows).

with obstruction. Abdominal ultrasound showed a complex mass in the hypogastrium, with a typical configuration of intussusception (fig. 1). Also, a small amount of fluid was seen within the intussusception. Oral contrast-enhanced CT images showed a round target-shaped mass in the mid-abdomen consisting of different densities with distended fluid-filled small-bowel loops (fig. 2).

Emergent laparotomy revealed ileoileal invagination approximately $70 \mathrm{~cm}$ to the ileocecal valve but no lead point. A partial ileal resection was performed.

\section{Discussion}

Intestinal intussusception in adults is rare, particularly idiopathic intussusception [3]. With the increasing use of ultrasound, CT and improved methods for examining the small bowel, intussusception is currently diagnosed more frequently before operations, as in our case. It is estimated that only $5 \%$ of all intussusceptions occur in adults and approximately $5 \%$ of bowel obstructions in adults are caused by intussusception [4].

In more than $90 \%$ of cases, an identifiable lesion resulting in a lead point is demonstrable [5]. In general, the majority of lead points in the small intestine consist of benign lesions such as neoplasms, inflammation, Meckel's diverticuli, appendix and adhesions. Malignant lesions (either primary or metastatic) account for 30\% of small-intestinal and $66 \%$ of colonic intussusception $[4,5]$.

In adults, the exact mechanism of intussusception is unclear. However, any lesion in the bowel wall or irritant within the lumen that alters normal peristaltic activity can initiate intussusception [3]. In our case, pregnancy might have contributed to the development of intussusception.

The clinical presentation of adult intussusception varies considerably. The most common presenting symptoms (i.e. abdominal pain, nausea and emesis) are mani- 
fest in only $20 \%$ of patients [6]. Other symptoms include fever, constipation, diarrhea, bleeding and abdominal distention. Common physical findings include abdominal distention, decreased or absent bowel sounds and abdominal mass $[2,4]$. The diagnosis of acute abdominal conditions during the early postpartum period is difficult due to nonspecific symptoms. A high index of suspicion and careful clinical evaluation are required to avoid misdiagnosis and delayed treatment. Our case had also nonspecific symptoms such as abdominal pain, nausea and emesis. We performed imaging studies (i.e. ultrasound and CT) to confidently diagnose or exclude significant pathologies.

Ultrasound is a very useful and appropriate technique in the diagnosis of intussusception both in children and in adults [7] as it was in our case. The classic features of intussusception include target and doughnut signs on a transverse view and the pseudokidney sign in the longitudinal view [8]. Ultrasound is an operator-dependent technique whose utility may be limited by obesity and air in distended bowel loops.

CT has been used to evaluate patients with intestinal obstruction and patients in whom intestinal intussusception is suspected. CT has been reported to be the most sensitive imaging method for detecting intussusception $[2,6,9]$. CT is also useful for the diagnosis of surrounding structures and when a malignancy is suspected. How- ever, CT may not reliably distinguish between a neoplastic lead point and a thickened bowel wall [10]. We also used CT to confirm the diagnosis of intussusception and evaluate surrounding structures. We observed a target appearance without a lead point on CT.

Most adults with intussusception require surgery to clarify the etiology of the lead point. Treatment usually requires resection of the involved bowel segment. Reduction can be attempted in small-bowel intussusception if the segment involved is viable and if malignancy is not suspected. In colonic intussusception, malignancy and resection are more likely. Therapeutic barium enema can be tried in a few selected cases where the underlying pathology is known [10]. In some patients, small-bowel intussusception may be an incidental finding. Careful observation may be indicated if imaging does not reveal an identifiable lead point, vascular compromise or bowel obstruction [11].

\section{Conclusion}

This case showed that when intussusception is suspected, an abdominal ultrasound should be performed even in patients with atypical symptoms. CT may be used to confirm the diagnosis.

\section{References}

$\checkmark 1$ Reijnen HA, Joosten HJ, DeBoer HH: Diagnosis and treatment of adult intussusception. Am J Surg 1989;158:25-28.

2 Eisen LK, Cunningham JD, Aufses AH Jr: Intussusception in adults: institutional review. J Am Coll Surg 1999;188:390-395.

3 Kretzschmar U, Weidenhammer K, Rexroth $\mathrm{W}$ : Idiopathic intussusception in adults. Röntgenblätter 1989;42:484-486.

4 Begos DG, Sandor A, Modlin IM: The diagnosis and management of adult intussusception. Am J Surg 1997;173:88-94.

5 Haas EM, Etter EL, Ellis S, Taylor TV: Adult intussusception. Am J Surg 2003;186:75-76.
6 Warshauer DM, Lee JK: Adult intussusception detected at CT or MR imaging: clinicalimaging correlation. Radiology 1999;212: 853-860.

7 Dicle O, Erbay G, Haciyanli M, Bora S: Inflammatory polyp presenting with intestinal invagination: sonographic and correlative imaging findings. J Clin Ultrasound 1999; 27:89-91.

8 Weissberg DL, Scheibe B, Ineopold GR: Ultrasonic appearance of adult intussusception. Radiology 1987;30:525-530.
\$9 Gayer G, Apter S, Hofmann C, Nass S, Amitai M, Zissin R, Hertz M: Intussusception in the adults: CT diagnosis. Clin Radiol 1998; 53:53-57.

10 Zubaidi A, Al-Saif F, Silverman R: Adult intussusception: a retrospective review. Dis Colon Rectum 2006;49:1546-1551.

11 Mateen MA, Saleem S, Rao PC, Gangadhar V, Reddy DN: Transient small bowel intussusceptions: ultrasound findings and clinical significance. Abdom Imaging 2006;31: 410-416. 